\title{
Author's Educational Program "Training of Innovative Project Activities" and Conditions of Its Inclusion in the System of Retraining of Stage Directors
}

\author{
Tatiana Portnova \\ A. N. Kosygin Russian State University
}

\begin{abstract}
The strategic aspects of the development of artistic endeavor in modern conditions are aimed at finding opportunities for the implementation of its principles in the system of multilevel education during the modernization period. The modern system of theatrical education imposes new requirements on the art community; there is a need for the introduction of innovative approaches which should promote not the replacement of traditional methods, but the expansion of their opportunities. The article considers the contents and structure of the system of retraining of stage directors upon the transition to modern theatrical design technologies. The competence-based approach realized by the author's educational program "Training of innovative project activities" and conditions of its inclusion in the system of retraining of theatrical directors provides for the development in students of the ability to think independently, and the formation of skills and abilities of using the gained knowledge in professional activity. The provisions of the article allow taking a new look at the development mechanisms of scenic creativity, and revealing the opportunities of innovative technologies not used at the moment. A new approach to the implementation of the program is considered in theatrical education both in the aspect of using computer methods, multimedia and other technology-related means and from the positions of interactive and introspective reference points in the project-theatric culture.
\end{abstract}

Keywords-Educational program, innovations, system of retraining, project activities, theatrical art direction

\section{INTRODUCTION}

Today around the world, projectivity is considered "as a defining style category of modern thinking, one of the most important typological signs of modern culture nearly in all its main aspects connected with the creative activity of the person" [28, pp. 87-99]. Modern studies on the use of design technologies in theatrical direction training show that it is one of promising pedagogical technologies having ample opportunities in the realization of many ideas and purposes favoring the development of various qualities of a creative person necessary for a modern theater worker, formation of updated knowledge, skills and practices in various neighboring areas. The advantages of the design approach over the traditional and known ones are its flexibility consisting in the opportunity for changing the priorities in the production process, the possibility of the economical use of the available resources and rather quick artistic realization of the ideological conception. The influence of digital technologies extends to the humanitarian aspects more and more widely today. The computer virtual reality increases the level of emotional and introspective activity of the author and can have an effect on the mechanism of synthesis of creative solutions in the art process. The research of new art forms, supported by the newest methods of computer modeling, activates creative search, can not only actively generate new ideas and forms, but also model various processes and situations of theatrical action. The creative process of the art director turns into a new type of design activity - design of the scenic environment. The figurative specifics is caused by an opportunity to perceptually perceive scenic objects and to operate them interactively. The virtual space has an ability to intensify emotional reaction, and the personal experience of the situation determines the humanistic potential of scenic design, which opens up new opportunities for author's design.

The structure and contents of the innovative program includes thematic material, starting from the project concept, types and directions of project activities, deals with the evolution of design and innovative technologies in the sphere of art, the stages of the development of computer and multimedia art practices, first of all, the creative works of theatrical directors in the sphere of project art.

The goal of research is to prove theoretically, develop and experimentally try the use of design technologies as a mean of various innovations introduction in the course of innovative development in the sphere of theatrical art direction

The research problems consist in:

- Identification of the approaches used at introduction of various innovations in the course of innovative development into theatrical education;

- Disclosure of the possibility of using design technologies for the innovative development of additional professional education institutions;

- Definition and development of the program contents including design technologies; 
- Check of introduction of the innovations connected with design technologies in practice of educational institutions.

\section{LITERATURE}

The works in the field of cultural studies, study of art, philosophy, methodology of design, psychology of creativity became a theoretical basis of the research. The general vector in the development and implementation of the program was determined by the main directions of public policy in the field of world education presented in normative documents [19, 2224].

The problems of the relationship of equipment and art are addressed in the publications of experts in the Western culture $[12,21,29]$.

The disclosure of the humanistic potential of computer virtual reality demanded generalization of studies in various fields of knowledge [16-18, 25-26].

The creativity process as a result of nonlinear thinking and emotional and rational human activity was addressed in the works in the field of psychology [2, 8-9].

The works devoted to the theoretical analysis of the problems of world scenography and esthetics of theater were of great importance for the research tasks of this article [3-5, $11,14,27]$. Those studies, where the professional specifics of the compositional arrangement of theatrical action is considered, means of art expressiveness are regarded, were also analyzed [6-7, 13]. The knowledge from such spheres as modern multimedia design, computer facilities and mancomputer interaction is also attracted $[1,3-4,10,15,20]$.

\section{METHODS}

The methods of research were the analysis of literature and international and Russian studies in the sphere of innovative development of creative educational institutions and drama schools; modeling; analysis and synthesis of experience of innovative activity and design in educational systems; ascertaining and educational experiments. The method of cultural and historical analysis in the treatment of the program subjects allows considering the historical evolution of a stage director's solutions, the tendencies of the development of production technologies in theater [17, 19]. The subjects connected with computer and media technologies in scenography as the new direction of development of production activity of the 21 st century in which practical application of opportunities of new technologies in the dramatized statements is considered (LED screens (board), mobile projective displays adapted for small halls and concert venues, projection and fog screens, plasma panels with different diagonals, multifunctional fixtures, media platforms, interactive glass, various production elements which are used in video projections, etc.) are of great importance [13].

The typological method in the disclosure of separate subjects of the course allows systematizing new production technologies and display of the dramatized representations and performances on groups. The technology of management and planning is considered in the form of the "Theatrical project" favoring the formation of culture of the theatrical process organization with the use of information technologies [22], representing a set of methods, production and program and technological means united in the technological chain providing collecting, storage, processing, output and distribution of information.

The method of figurative and stylistic analysis of theater art works gives the chance to estimate the art level of the dramatized productions, to see their originality [23]. The virtual art, which entered into modern theater at the beginning of the 21st century, brought into theatrical show unique opportunities for reality imitation, reflection of life in threedimensional display of the action scene, transformation of time and space; contributed to the improvement of stagecraft. In modern time, new technologies are applied both to the performances shown on closed theatrical platforms and to the mass shows which are carried out in the conditions of open space of the urban environment.

Theoretical and art-practical judgment of the main aspects of production process in modern theater [24] ends with the subjects lighting up the use of information technologies in the organization of theatrical process. On the one hand, information technologies allowed providing to the viewer online broadcasting of world premieres and a form of interactive involvement in theatrical action. The possibilities of information scenography changed organizational processes of tour activity, made it possible to quickly create the scenic space of performances in rooms and open areas, brought a spectacular component of the creative plan into performance. On the other hand, information technologies in modern theater allowed creating new visual culture [12, 16], having supplemented the emotional aspect of the traditional graphic and picturesque technology of sketches creation with more detailed professional characteristics: variability, spatial composition, accurate scale, abundance of factures and special effects, possibility of exact reproduction and transmission in digital format.

The equipment and material procurement of the program assumes the existence of not only specially equipped multimedia audiences in which it is possible to deliver the necessary theoretical material accessibly and effectively, but also scenic platforms, making it possible to use in practice modern information educational technologies at all stages of production process: from computer sketches of scenography and 3D prototyping to practical implementation of performance [1], as well as to realize the objectives, to trace the planned results of educational and creative activity, to control individual, group, project and independent work of students

\section{RESULTS AND DISCUSSION}

The author's program of the discipline "Design technologies in art" is made according to the requirements of the FSES for the direction and profile of training "Direction of dramatized performances" of the main educational program of higher education; it can be taken as a basis and is adapted in the program of additional professional education. The 
requirements to conditions of implementation of the additional professional education program are comprised of the approximate level of the requirements of entrance tests for the program "Design technologies in art". The previous education level of the applicant - secondary professional education, incomplete higher and higher professional education. Admission tests: colloquium (clarification of the idea of orientation and professional duties of a stage director); analysis of dramatic work.

The methods and means of the organization and realization of educational process according to the program can be:

- The methods and means focused on theoretical training lecture; seminar, practical trainings, independent work of students, consultation, forms of theoretical knowledge control: end-of-term test and examination;

- The methods and means focused on practical training: report, creative work, final qualification paper.

The assessment of the quality of the program capture has to include the current control of progress, intermediate complex tests and final assessment. The concrete forms and procedures of current, intermediate control for each discipline of the curriculum of the program and final control of knowledge are developed by the departments of the academy and are reported to students. To test the compliance of a student's personal achievements to stage-by-stage and final requirements of the appropriate program of professional retraining, the funds of estimating means are created, which include tasks, review work, tests and control methods, making it possible to estimate knowledge, abilities and level of the acquired competences. The funds of estimating means are developed and approved by the departments of the academy. The fund of estimating means for current, intermediate and final assessment of students of the professional retraining program "Design technologies in art" represents the set of methodical materials intended for estimating the compliance of the level of students' training to the qualification requirements of the acquired competences at a certain stage of mastering the program or upon the graduation.

The final state assessment of the graduates who finished training on the program of professional retraining "Design technologies in art" includes: state exam in the direction of training "Theory and history of art culture", which allows revealing the theoretical preparation for the solution of job tasks - presentation of a final certification work on production work of the director's direction. The final certification work consists of practical and theoretical parts. The practical part represents the prepared creative theatrical project, and the theoretical part - the justification of the practical part disclosing the corresponding aspects of history, theory and technique of its creation and management in art and production process. The state exam provides a possibility of deep and multifaceted examination of knowledge, acquired by the student during training. The examination cards include the most important questions of cross-disciplinary character, making it possible to reveal the degree of the formation of common cultural competences, namely: to what extent the graduate of the program masters the culture of thinking, whether he/she is capable of generalization, analysis, and perception of the necessary information.

The structure of the final certification work consist of: the text part, the text typed on the computer (up to 60 pages); - a CD with the electronic record of all materials of the final certification work. The text part consists of the introduction, main part, conclusion, the list of references, and text appendices. The introduction presents the relevance, object and topic of research, the purpose and tasks, the methodological base of research, its theoretical, methodical and applied importance. The main part of the text includes: scientific-theoretical section containing historical, ethnographic or art history data; methodical section containing the description of the author's activity in the field of the production solution with the use of new design technologies, solutions of the tasks appointed by professional activity according to professional competences.

In the conclusion of the final certification work, the main conclusions according to all sections of work are given, and the recommendations on the use of practical materials in educational process and professional activity are presented. At the presentation, it is necessary to present a descriptive range of the creative project (video, photo, drawings, and other graphic materials). It should be noticed that the process of retraining, advanced studies, training of the basic principles of the production work connected with stage setting is specific because of the fact that not each production director has art abilities and spatial imagination. Besides, the lack of facilities both in educational and in creative production process quite often results in the minimalism in scenography. The application of the methods of the computer modeling of the performance helps to solve these problems, to develop the creative idea in the format of "Theatrical project", and favors the creation of the director's concept. The developed technique involves using in the course of design the general principles of compositional form creation specific for the chosen art style. The list of references is drawn up according to standard requirements. The text appendices include illustrative material, and reference data. The final certification work presentation is carried out according to the established educational institution's order.

The practical importance of the developed author's program consists in the creation of scientific and methodical base of increasing the effectiveness of mastering the innovations and effective mechanisms, ensuring the systematic innovative development of stage directors in the conditions of the mass character of innovative activity.

\section{CONCLUSIONS}

The organization of a system of retraining of stage directors upon the transition to modern theatrical design technologies implements the competence-based approach that provides for the development in students of the ability to think independently, and the formation of skills and abilities of using the gained knowledge in professional activity by:

- Ability and readiness to exercise great professional skills and to show a good command of directing and production technology, knowledge of historical and 
modern engineering procedures during creation of various dramatized performances;

- Understanding that the stage direction of a holiday and performance is connected with other art forms and related to the corresponding disciplines in humanitarian, social, natural and physical sciences, actively influences all aspects of human activity;

- Demonstration of ability to understand and analyze the ideas and the phenomena in modern society, art and culture, ability to build the argument (both in written and oral form) for justification and protection of one's point of view;

- Mastering the skills of communication, free and confident use of professional terminology for the purpose of bringing art information to consciousness of participants of art and creative process in an available form, knowledge of professional terminology.

So, as we see, in the modern art the tendencies of the interaction of art languages, crossings of their semantic fields are shown. New technologies enable the author of the project to reincarnate from the actor into the artist or in his creation, capable to influence on development and modification of the art work. The principle of interactivity as a form of coauthorship of the director and the audience alters the theatrical image, and favors the variety of the used aspects and methods of art mastery. The complexity of the solution, the ability to create the concept and to operate the project causes the development of training programs of this profile, the purpose of which consists in the formation of special knowledge of organizational development regularities and the features of design activity in the sphere of theater. The consideration of various modern approaches to structuring the design activity allowed creating the specialized program for studying theater art, organization, arrangement and creation of theatrical performances, which can be applied both in creative higher education institution and on the professional stage and determine its content.

The interpretation of the results of the experiment on the use of design technologies in teaching at a number of institutes of Moscow and educational organizations of postgraduate education showed the efficiency of the developed author's program favoring the formation of positive educational motivation, development of various types of creative thinking, skills of organization of own activities and design skills. This program is currently important not only in the context of the analysis and creation of interesting multimedia solutions applied in scenography but also in the context of further development of world theatrical education, in which traditions should smoothly interact with innovative technologies.

\section{REFERENCES}

[1] Aldoshina, I.A., Soshnikov, V.D., Poznin, V.F., Denisov, A.V., Ignatov, P.V., Kuznetsov, I.R., \& Shekter, T.Ye. (Eds.) (2010). The Art of Multimedia. Multimedia and Technics. St. Petersburg: SPbUHSS

[2] Arnheim, R. (1994). New Essays on the Psychology of Art. Moscow: Prometey.

[3] Astafyeva, T.V. (2009). The Modelling of Modern Theatrical Process. Innovations and Investments, 4, 112-116.
[4] Astafyeva, T.V. (2009). The Technology of Virtual Worlds in Theater. In M.B. Ignatyev, \& M.A.Vus (Eds.), Informatics for Sustainable Development (pp. 152-157). Saint Petersburg: SPSTSK, Poligraf express.

[5] Astafyeva, T.V. (2011). The Technologies of Creative Search in Modern Theatre. In Modern Art in the Context of Globalization: Science, Education, Art Market: The Materials of the 4th Russian National Research and Practice Conference, 4 February 2011 (pp. 138-139). Saint Petersburg: SPbUHSS.

[6] Bazanov, V.V. (2005). The Technology of Scene. Moscow: Impuls-svet.

[7] Beryozkin, V.I. (1997, 2001). The Art of Stage Design of the World Theatre. Book 1. Ab Origin to the Middle of the 20th century. Moscow: Editorial URSS. Book 2. The Second Half of the 20th Century: In the Mirror of Prague Quadrenniale 1967-1999. Moscow: Editorial URSS

[8] Wiener, N. (2003). God and Future (Transl. from English). Moscow: AST.

[9] Gabrichevsky, A.G. (1994). Space and Time. The Problems of Philosophy, 3, 134-147.

[10] Galeev, B. (n.d.). The Early Experiments of SDB "Prometheus" in the Video-Art. http://prometheus.kai.ru/videartr.htm.

[11] Gitelman, L.I. (2004). The Art of Stage Direction Abroad. Saint Petersburg: SPSATA.

[12] Godovanets, Yu.A. (2004). Preservation of Cultural Values: Formation of the Advanced Model's Culturological Fundamentals. Moscow: MAKS Press.

[13] Gromov, N.N. (2006).The Horizons of Scenography. Art Convention in the Art of Stage Backdrop. St. Petersburg: Aktzioner i K.

[14] Dvoretsky, S., Puchkov, N., Muratova, Ye. (2003). The Formation of Project Culture. High Education in Russia, 4, 138-144.

[15] Dvorko, N.I. (2004). The Art Direction of Multimedia: Genesis, Specifics, Aesthetic Principles: Extended abstract of dissertation for the degree of Doctor of Art History. Moscow.

[16] Drikker, A.S. (2000). Evolution of Culture. St. Petersburg: Akademicheskii proekt.

[17] Zhidkov, V.S. (1995). Cultural Policy and Theater. Moscow: Izdat.

[18] Kryukova, Ye.A. (2000). Theoretical Fundamentals of Designing and Application of Personal-Amplifying Pedagogical Instruments: Dissertation of the Doctor of Education. Volgograd.

[19] Astafyeva, O.N. (Ed.). (2010). Culture and Cultural Policy: the Materials of Scientific and Methodological Seminar (Issue 8: Cultural Requirements of Youth: Dynamics in the Conditions of Sociocultural Changes). Moscow: RACS Publishing House.

[20] Levshina, Ye. (2004). Computer in the Theater - Yesterday, Today, Tomorrow. Scene, 4, 4-5.

[21] McLuhan, M. (2003). Understanding Media: The Extensions of Man. Moscow: CANON-Press C.

[22] Polat, Ye.S. (Ed.). (2003). New Pedagogical and Information Technologies in the Educational System: Training manual for students of pedagogical universities and career development system of teaching staff. Moscow: Akademiya.

[23] Education, Science, and Culture in the Contemporary World: the Materials of International Scientific Web-Conference "Basic Ideas of the UNECSO in Modern Education, Culture and Science" (Moscow, March 2013). (2014). Moscow: Pashkov dom.

[24] Sobranie Zakonodatel'stva Rossiiskoi Federation [SZ RF] [Collection of Legislation of the RF] 2011, No. 25, Item 3650.

[25] Prokopyeva, N.I. (2005). Professional and Pedagogical Training of Students in the Process of Project-Based Learning: Extended abstract of dissertation of the Candidate of Pedagogic Sciences. Novosibirsk.

[26] Rosin, V.M. (1984). Project Development as an Object of Philosophical and Methodological Research. The Problems of Philosophy, 10, 110-112.

[27] Sidorenko, V.F. (2007). Aesthetics of Project Oeuvre. Moscow: ARRITA.

[28] Sidorenko, V.F. (1984). The Genesis of Project Culture. The Problems of Philosophy, 10, 87-99.

[29] Toffler, A. (2004). The Third Wave (Transl. from English). Moscow: AST. 